\title{
Geospatial tools for assessing land degradation in Budgam district, Kashmir Himalaya, India
}

\author{
Mehnaz Rashid ${ }^{1, *}$, Mahjoor Ahmad Lone ${ }^{1}$ and Shakil Ahmad Romshoo ${ }^{2}$ \\ ${ }^{1}$ National Geophysical Research Institute, Hyderabad 500 606, India. \\ ${ }^{2}$ Department of Geology and Geophysics, University of Kashmir, Srinagar 190 006, India. \\ *e-mail:geo.mehnaz@gmail.com
}

\begin{abstract}
Land degradation reduces the ability of the land to perform many biophysical and chemical functions. The main aim of this study was to determine the status of land degradation in the Budgam area of Kashmir Himalaya using remote sensing and geographic information system. The satellite data together with other geospatial datasets were used to quantify different categories of land degradation. The results were validated in the field and an accuracy of $85 \%$ was observed. Land use/land cover of the study area was determined in order to know the effect of land use on the rate of land degradation. Normalized differential vegetation index (NDVI) and slope of the area were determined using LANDSAT-enhanced thematic mapper plus (ETM+) data, advanced space-borne thermal emission and reflection radiometer, and digital elevation model along with other secondary data were analysed to create various thematic maps, viz., land use/land cover, geology, NDVI and slopes used in modelling land degradation in the Kashmir Himalayan region. The vegetation condition, elevation and land use/land cover information of the area were integrated to assess the land degradation scenario in the area using the ArcGIS 'Spatial Analyst Module'. The results reveal that about $13.19 \%$ of the study area has undergone moderate to high degradation, whereas about $44.12 \%$ of the area has undergone slight degradation.
\end{abstract}

\section{Introduction}

Land degradation is defined as long-term loss of plant and animal productivity and diversity useful to human beings (Milton et al 1994). The Food and Agriculture Organization (FAO 1980) defines the concept of land degradation as the deterioration or total loss of the productive capacity of the soils for present and future use. Globally, an estimated 954.8 million hectares of land is affected by salinity (Szabolcs 1992). Also about 1.9 billion hectares of land worldwide (an area approximately the size of Canada and the USA) are affected by land degradation (United Nations 1997). These figures will have serious implications on the future of humanity. The livelihoods of more than 900 million people in some 100 countries are now directly and adversely affected by land degradation (United Nations 1994). Land degradation is observed in all agro-climatic regions on all continents. The countries of the developing world, particularly, those in the arid and semi-arid zones, are the most seriously affected (UNEP 1986). The global assessment of soil degradation estimated that about 13\% (850 million hectares) of the land in Asia and the Pacific region is degraded.

Desertification, land and resource degradation have been identified as high probability and high impact problems which could result in human or environmental disasters (UNEP 1998).

Keywords. Remote sensing; geographic information system (GIS); Budgam; Kashmir Himalaya; land degradation; normalized differential vegetation index (NDVI). 
Overexploitation of environmental resources by humans and by grazing animals, non-scientific political decisions or economic policies, etc., add external impetus to land degradation (Ning 1997).

Salt-affected soils are reported to cover an estimated 7.0 million hectares (Abrol and Bhumbla 1971). Water logging, closely associated with salinization and alkalinization, continues to be a threat to sustained irrigated agriculture, affecting an estimated 6 million hectares of fertile land in India (National Commission on Agriculture 1976).

The most significant landscape function affected by land degradation is the hydrologic balance of catchments. Unfavourable soil-surface characteristics of degraded lands and a lack of adequate plant cover lead to reduced surface retention and infiltration, and to higher surface runoff. This results not only in reduced soil moisture content in the soil profile, but also increased rates of soil erosion (Lal 1990). Particularly in dry areas, reduced available soil moisture in turn negatively affects plant growth and thus further reduces biomass production and protective soil cover. A large number of studies have been carried out using different methods of remote sensing and geographic information system (GIS) to determine the extent of land degradation. Mitchell (1981); Stephen et al (1981); Karale et al (1983); Pickup and Nelson (1984); Pickup and Chewings (1988); Sharma and Bhargava (1988); Dwivedi (1992); Dwivedi et al (1997); Dwivedi and Sreenivas (1998); Pickup et al (1998); Zhang et al (2003); Symeonakis and Drake
(2004); Chikhaoui et al (2005); Wang et al (2006) and Kiage et al (2007) have developed various techniques for mapping, monitoring and assessing degraded lands. About 4131,527 hectares of land in Jammu and Kashmir is under different categories of soil erosion, out of which Budgam district accounts for 115,044 hectares of soil erosion and 4466 hectares under stream bank erosion (ENVIS 2003). Based on these environmental reports that are ultimately linked to land degradation, the status of land degradation was investigated using remote sensing and GIS. This will lead to proper monitoring of environmental changes and development of a sustainable land-use management plan for the study area. It was in this backdrop that the objective to study indicators such as vegetation, slope and land use/ land cover were undertaken (Symeonakis and Drake 2004).

\section{Study area}

Budgam of Jammu and Kashmir (figure 1), located in the northern part of India between $34^{\circ} 42^{\prime}-$ $34^{\circ} 50^{\prime} \mathrm{N}$ and $74^{\circ} 24^{\prime}-74^{\circ} 54^{\prime} \mathrm{E}$, covers an area of $1291 \mathrm{~km}^{2}$. About $6 \%$ of the state's population resides in Budgam. The area supports a varied topography exhibiting altitudinal extremes of 1550 to $4700 \mathrm{~m}$ above mean sea level. From southwest to northeast, the area consists of the lofty PirPanjal, and flat-topped karewas as foothills and

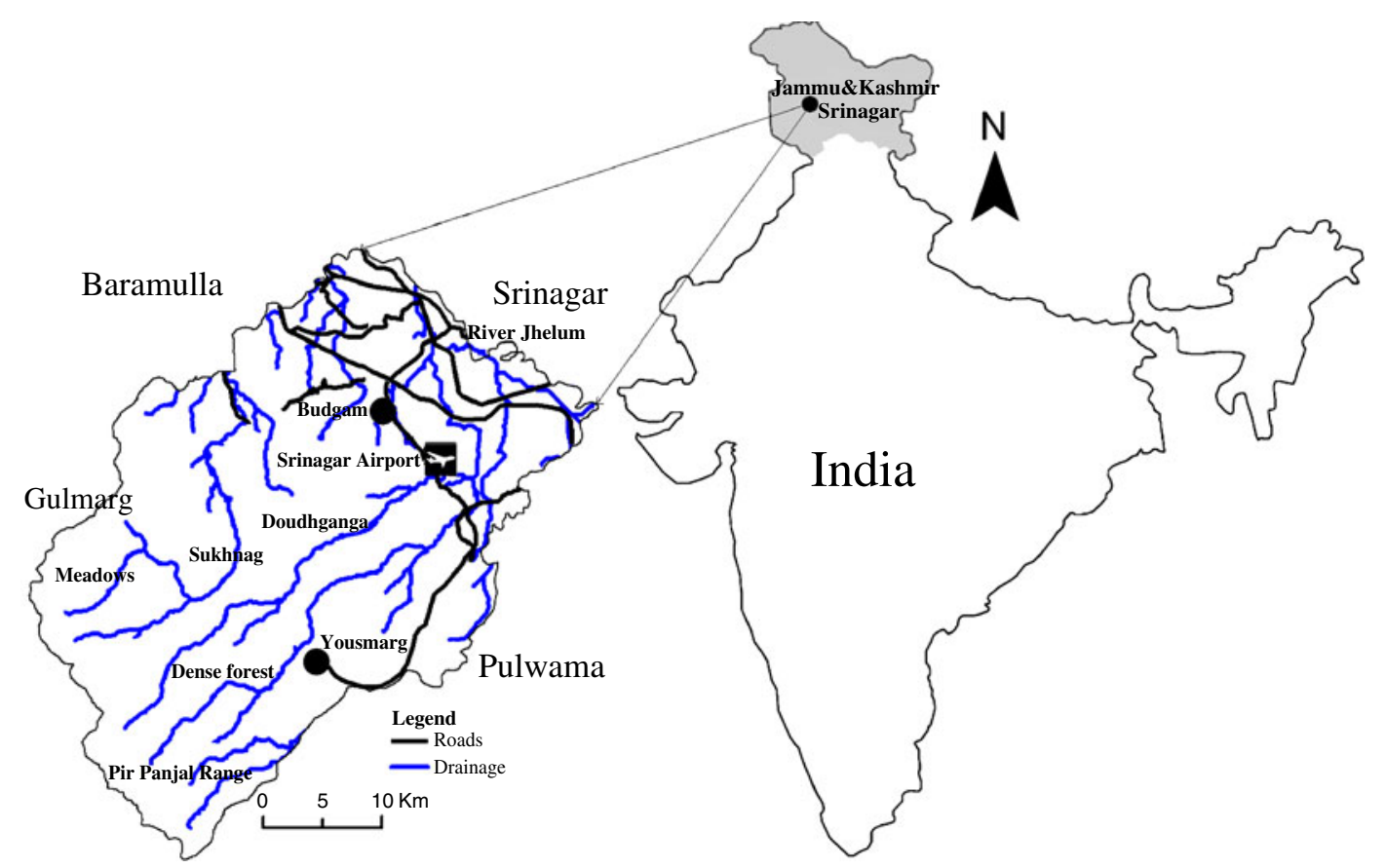

Figure 1. Location map of the study area. 
plains. The Pir-Panjal mountain range covers the Kashmir valley on the south and southwest, separating it from the Chenab valley and the Jammu region. The karewa formation is a unique physiographic feature of the area. These are lacustrine deposits of the Pleistocene age composed of clays, sands, and silts. The soils in the area are generally of three types, viz., loamy soil, karewa soil and poorly developed mountain soil (Raza et al 1978). Climate of the area is temperate type with warm summers and cold winters. The mean annual temperature is $20.2^{\circ} \mathrm{C}$. The precipitation and temperature values for 2008 as well as long-term climatological details are given in figure $2(\mathrm{a}, \mathrm{b})$. Average annual rainfall in the area is $669.1 \mathrm{~mm}$ and maximum precipitation occurs during March to April when westerly winds strike the northern face of the Pir-Panjal Mountains. The long-term rainfall intensity is shown in figure 2(c). These climatic conditions exert a strong influence on types of vegetation cover, and control land-use/land-cover types which are divided into agricultural land with various types of crops and trees, forests, karewas, meadows and wetlands. The natural vegetation of this region has been substantially modified through several thousand years of human activities.
Almost all remaining permanent vegetation represents forests mostly at higher altitude and various types of trees in low-lying areas. Human interference in the area has resulted in deterioration of wetland that is habitat to thousands of migratory birds. Deforestation is a great threat to the rich biodiversity of the area.

The geology of the area is quite diverse ranging from Archean to Recent; Pir-Panjal represents rocks of a wide range in age. The commonest of the rocks present in the area are Panjal traps, karewa and alluvium. Although karewa overlays most of the low-lying areas, the areas near river Jhelum are covered with recent alluvium. Principal component analysis (PCA) with principal components (PC1 to PC6) was generated. PC3 and PC4 were very useful in distinguishing various geological formations. The integrated use of PCA images, ground survey and existing geological map (Wadia 1975) were used to distinguish various geological units of the area (figure 3a).

Drainage of the area is quite significant with most of the drainage flowing into river Jhelum. Dudhganga and Shaliganga are the important tributaries of river Jhelum. Dudhganga flows from Ludurmarg and rises in the central Pir-Panjal near

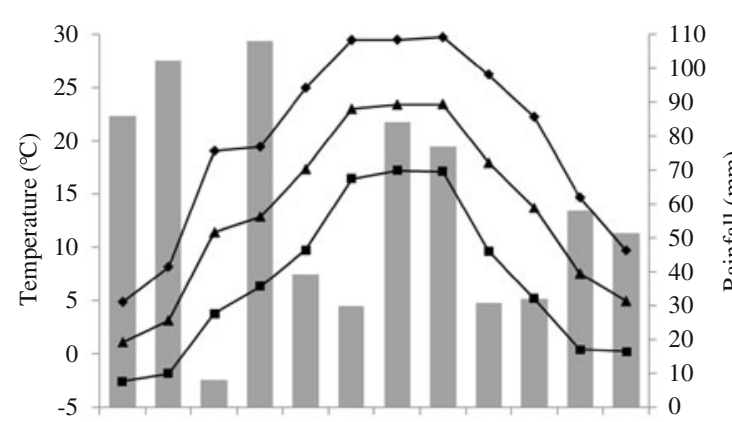

(a) Jan Feb Mar Apr May Jun Jul Aug Sep Oct Nov Dec

= Rainfall $08 \rightarrow$ Max Temp $08 \rightarrow$ Min Temp $08 \rightarrow$ Avg Temp 08

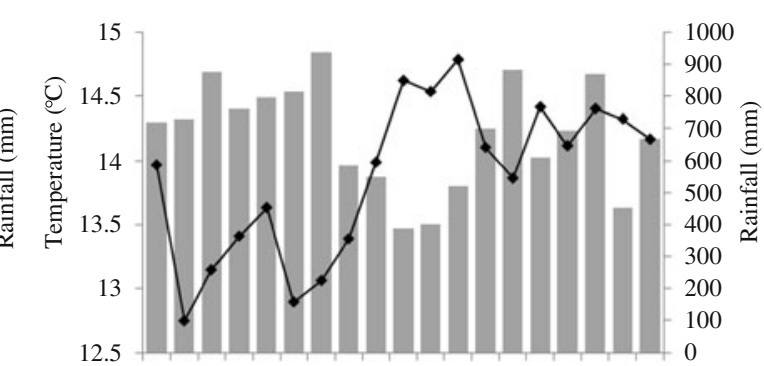

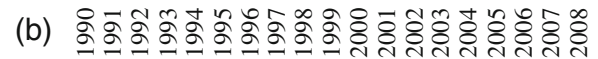

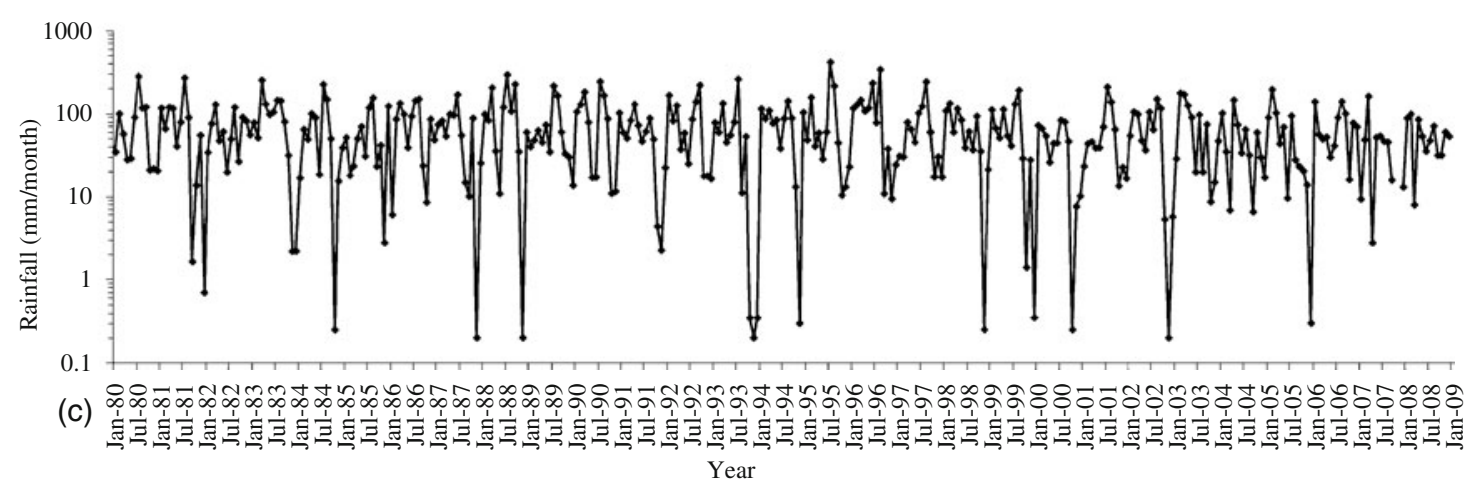

Figure 2. Meteorological details viz., temperature $\left({ }^{\circ} \mathrm{C}\right)$ and rainfall $(\mathrm{mm})$ of the study area. (a) Temperature $\left({ }^{\circ} \mathrm{C}\right)$ range and rainfall $(\mathrm{mm})$ pattern for the year 2008. (b) Average annual temperature $\left({ }^{\circ} \mathrm{C}\right)$ and precipitation (mm) from 1990 to 2008. (c) Rainfall intensity given as mm per month from 1980 to 2008. 


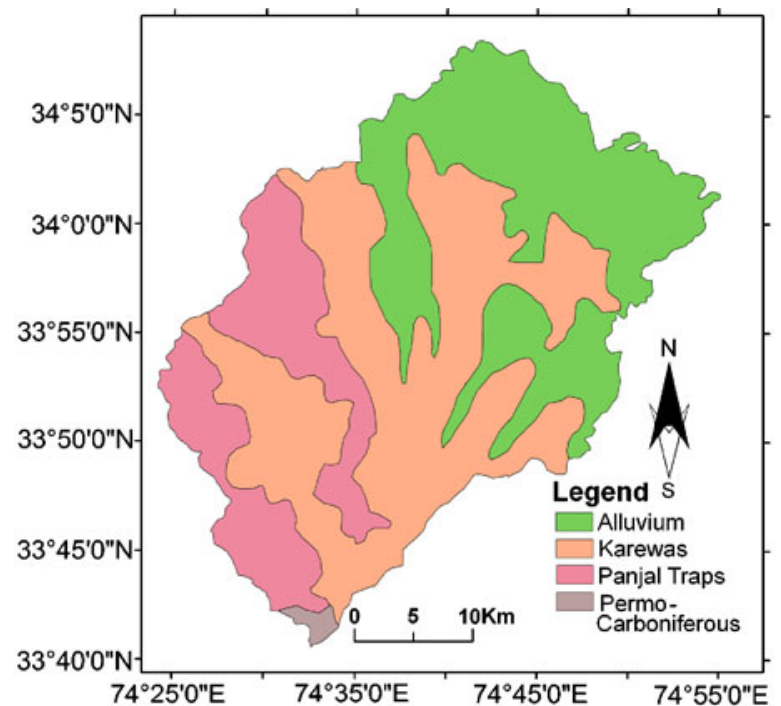

(a)

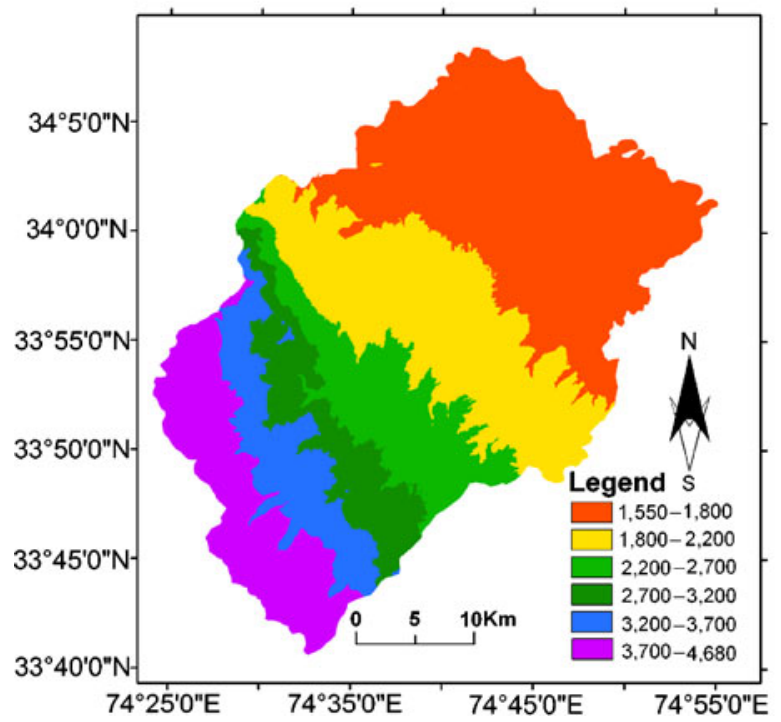

(c)

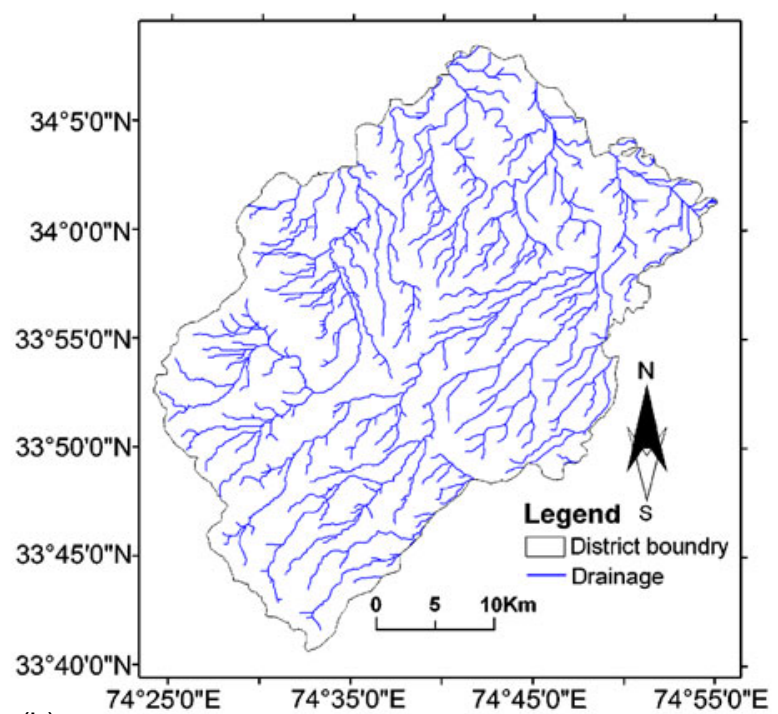

(b)

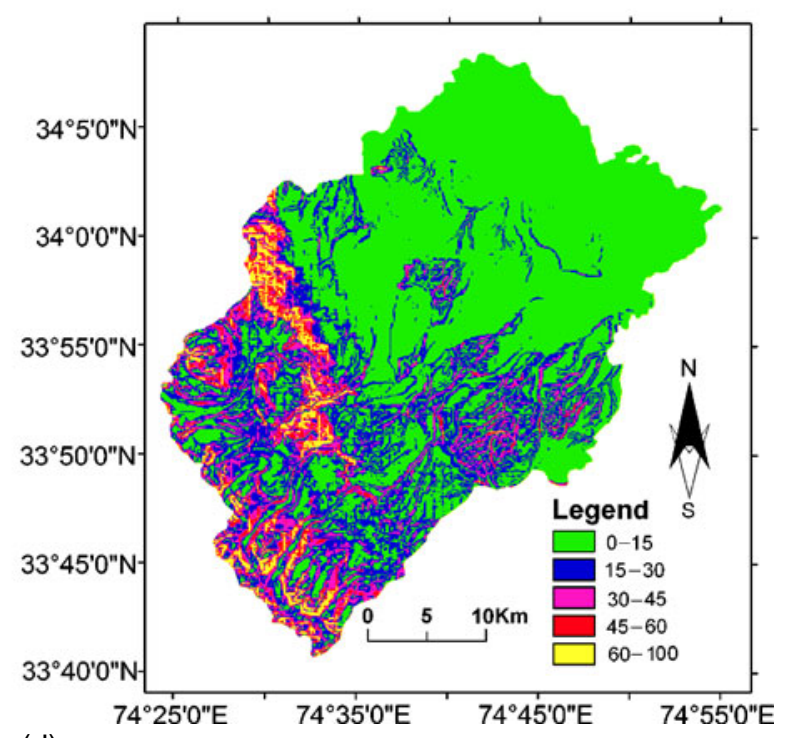

(d)

Figure 3. (a) Geology of the study area as derived from PCA and existing geological map after (Wadia 1975). (b) Drainage network of the study area derived from ASTER $30 \mathrm{~m}$ DEM. (c) ASTER $30 \mathrm{~m}$ digital elevation model revealing general topography of the study area. (d) Map showing the slope (in percent) of the study area generated from ASTER 30 m DEM.

Tatakuti mountain while Sukhnag forms its major tributary (figure $3 \mathrm{~b}$ ).

\section{Materials and methodology}

Landsat-enhanced thematic mapper plus (ETM+) data of 2008 and advanced space-borne thermal emission and reflection radiometer (ASTER) digital elevation model (DEM) with spatial resolution of $30 \mathrm{~m}$ were used in this study. The multispectral satellite image contains seven spectral bands, i.e., bands 1-3 represent the visible part of the electromagnetic spectrum with wavelengths of $0.450-$ $0.515,0.525-0.605$ and $0.630-0.690 \mu \mathrm{m}$, respectively. Band 4 represents the near infrared (IR) with wavelengths of $0.760-0.900 \mu \mathrm{m}$ and bands 5 and 7 represent mid IR with wavelengths of $1.550-1.750 \mu \mathrm{m}$ and $2.080-2.350 \mu \mathrm{m}$. Band 6 is present in the thermal IR, however, the band is not taken into account in this study. Satellite data are distorted by earth's curvature, relief displacement, and acquisition geometry of satellites (variation in altitude, aspect, velocity and panoramic distortion). For this study, the satellite data was geometrically and radiometrically corrected.

The Survey of India (SOI 1975) topographic maps $43 \mathrm{~K} / 9$ and $43 \mathrm{~K} / 13$ with a scale of 1:50,000 of the area were first scanned and then registered using Erdas Imagine software. For the registration, ground control points at the intersection of 


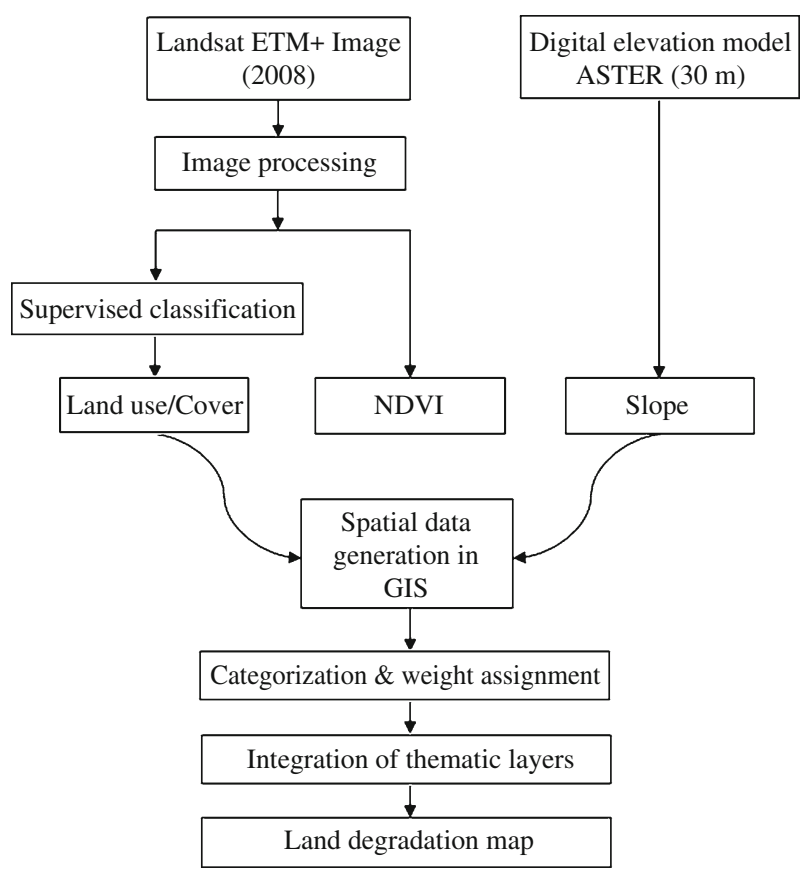

Figure 4. Flow chart of methodology adopted to determine land degradation.

latitude-longitude were selected. The process of image to map registration was then adopted for the registration of scanned imageries with process SOI topographic maps (Erdas Imagine 1999). The steps involved in the methodology for this study are summarized in figure 4 .

The geological map was prepared by PCA (PC1, PC2-PC6) of Landsat ETM+ image along with existing geological map, ground survey and other ancillary data. The PCA originally known as Karhunen-Loeve transformation (KL-transformation) is used to compress multi-spectral datasets and reduces the data redundancy (Jensen 1996). The transformation of the raw remote sensing data using PCA results in new principal component images that is more interpretable than the original image (Pal et al 2007). In this study,

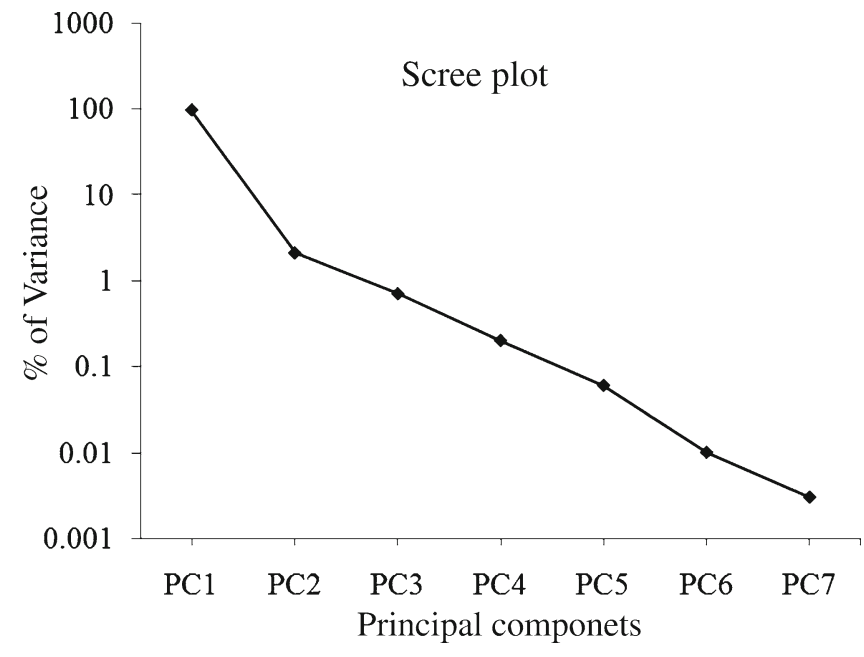

Figure 5. Scree plot approach to distinguish principal components of 2008 Landsat ETM+ image.

PC1-PC6 images were generated; PC3 and PC4 were found more useful in data interpretation as they contain more information about the lithology of the study area. Eigenvectors, eigenvalues and percentage of variance were computed for all the principal components and are given in table 1 . The scree plot (figure 5) helped to distinguish between the different principal components.

The imagery was visually interpreted to prepare land use/land cover map using knowledge-based supervised classification in Erdas Imagine. The output of the supervised classification was divided into 15 land cover classes. Each land use/cover class was then validated by visual inspection of original images, reference data, and ground survey of the study area. The judgement metrics for the preparation of land use/land cover map of the study area based on visual image interpretation is given in table 2.

Drainage and slope map of the area were derived from ASTER (30 m) DEM using ArcGIS 'Hydrology Module' and Erdas Imagine, respectively. Normalized differential vegetation index (NDVI) was

Table 1. Statistics of principal components derived from PCA of Landsat ETM+ image.

\begin{tabular}{|c|c|c|c|c|c|c|c|}
\hline \multirow[b]{2}{*}{ ETM-band } & \multicolumn{7}{|c|}{ Eigenvectors } \\
\hline & PC1 & $\mathrm{PC} 2$ & PC3 & $\mathrm{PC} 4$ & PC5 & PC6 & $\mathrm{PC} 7$ \\
\hline 1 & 0.21 & 0.45 & -0.32 & -0.02 & 0.23 & 0.59 & 0.48 \\
\hline 2 & 0.18 & 0.46 & -0.16 & -0.64 & 0.01 & 0.16 & -0.83 \\
\hline 3 & 0.19 & 0.56 & -0.04 & -0.31 & -0.25 & -0.64 & 0.25 \\
\hline 4 & 0.23 & 0.23 & 0.23 & 0.89 & -0.17 & -0.07 & 0.04 \\
\hline 5 & 0.25 & 0.12 & 0.87 & -0.27 & 0.19 & 0.19 & 0.01 \\
\hline 6 & 0.57 & -0.24 & -0.18 & 0.063 & 0.67 & -0.34 & -0.03 \\
\hline 7 & 0.66 & -0.36 & -0.1 & -0.15 & -0.59 & 0.21 & 0.007 \\
\hline Eigenvalues & 12624 & 273.104 & 91.82 & 31.02 & 8.468 & 1.55 & 0.504 \\
\hline$\%$ of variance & 96.88 & 2.09 & 0.7 & 0.2 & 0.06 & 0.01 & 0.003 \\
\hline
\end{tabular}




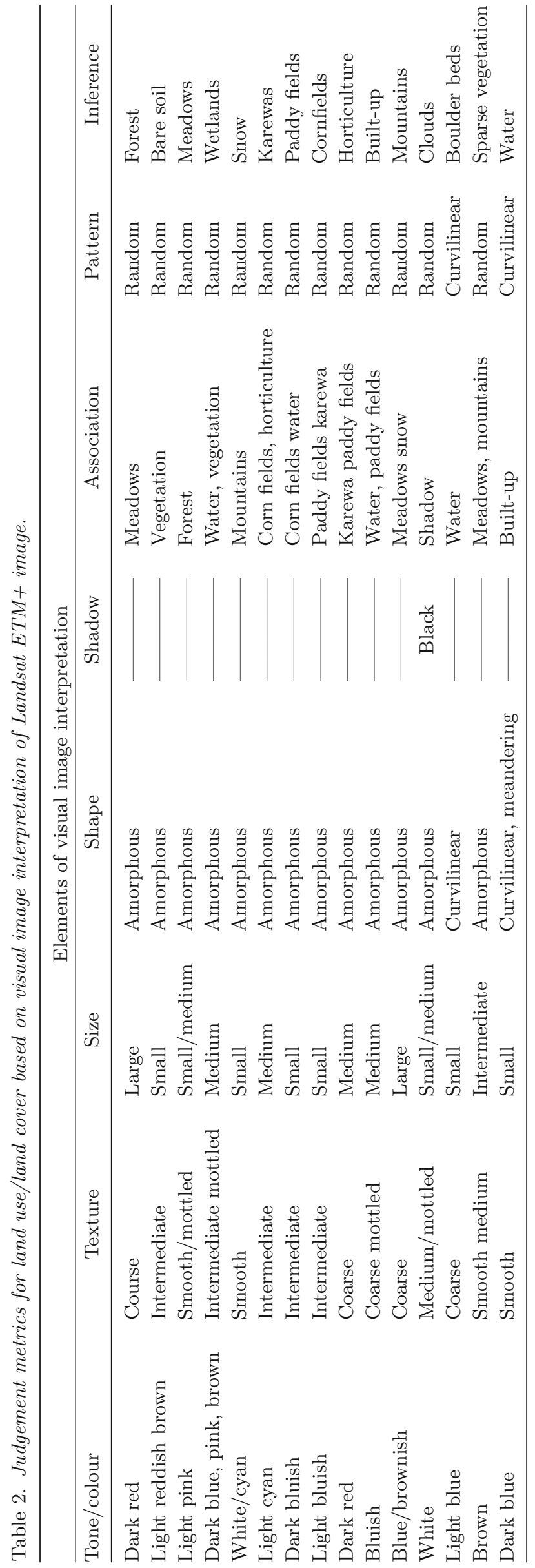

generated from the ETM+ image in Erdas Imagine. In the NDVI, the difference between the nearIR and red reflectance bands is divided by their sum. In case of Landsat imagery, band 4 represents near-IR band and band 3 represents the red band.

The scan line corrector (SLC), a small mirror in the optical path of the (ETM+) instrument, failed on 31 May 2003. The function of the SLC is to compensate for the forward motion of the satellite during data acquisition. As a result of the SLC failure, individual image scans overlap in some parts of images acquired thereafter, while leaving large physical gaps in others. On an average, about $22 \%$ of the total image is missing in the data of each scene. A small area of about $5 \%$ on the $\mathrm{N}-\mathrm{E}$ side of the study area was affected by scan line and the data gaps were filled by Erdas-based modelling. Different thematic maps generated using satellite data are geology, drainage, land use/land cover, NDVI and slope. All the maps were converted to raster data using $30 \times 30 \mathrm{~m}$ grid cell size and georeferenced to common reference point in the universal transverse mercator plane coordinate system (zone 43).

To determine a more accurate status of land degradation, all the themes (vegetation, land use/ land cover and slope) were integrated using the 'Spatial Analyst Module' of ArcGIS. Each theme and its individual classes were assigned weight and rank considering the works of Symeonakis and Drake (2004) and Kiage et al (2007), and were based on their individual role in land degradation. A weighed overlay analysis methodology was attempted by applying ArcGIS. Areas with least vegetation, higher slope and karewa type land cover, have been assigned higher ranks for land degradation. Similarly, areas with a high vegetation cover, low slope and forest type land cover are assigned low ranks for land degradation. The resultant composite coverage was classified into four classes: (1) non-degraded, (2) slightly degraded, (3) moderately degraded and (4) highly degraded.

\subsection{Validation studies}

The ground survey was carried out for six days to validate the legends. Most of the places in the area were visited and information about different land use/land cover and degraded lands was collected. Satellite images, global positioning system and the SOI topographic maps were used during field survey to evaluate the generated geology, land use/land cover and land degradation maps. Accuracy assessment was performed for land use/ land cover and land degradation maps. The result of the accuracy assessment was a confusion matrix showing errors of omission (producer's accuracy) 
and commission (user's accuracy) and a kappa coefficient. The overall classification accuracy for each map was computed by dividing the sum of all the correctly classified pixels (diagonal of the confusion matrix) by the total number of pixels in the confusion matrix. The kappa coefficient which is one of the most popular measures of addressing the difference between actual agreement and chance agreement was also computed. The kappa coefficient is basically the proportion of agreements after chance agreement has been excluded. Its upper limit is 1.00 (total agreement). Complete agreement at a chance level has a coefficient of zero.

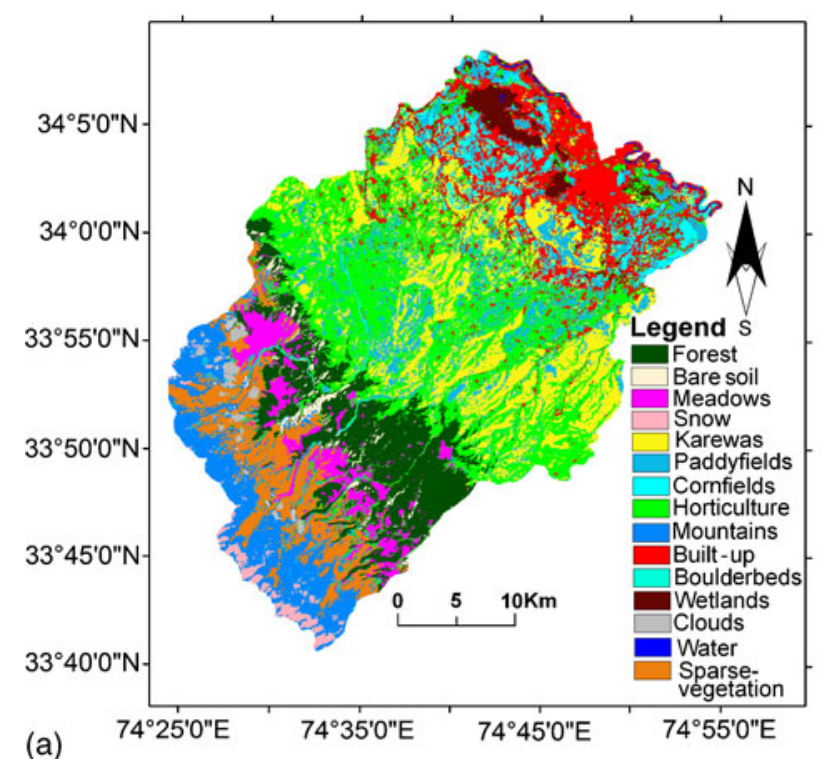

\section{Results and discussion}

\subsection{Slope}

Slope of an area represents steepness or inclination of an area determined from two points on a line. Slope plays a vital role in soil erosion in hilly terrain as found in the study area. A steep slope will cause more runoff and will enhance the soil erosion in absence of vegetation cover leading to land degradation as can be seen in karewas in the area. The results reveal that the slope of an area determined from the DEM (figure 3c) ranges from $0-15$ in low-lying areas, $15-30 \%, 30-60 \%$ and

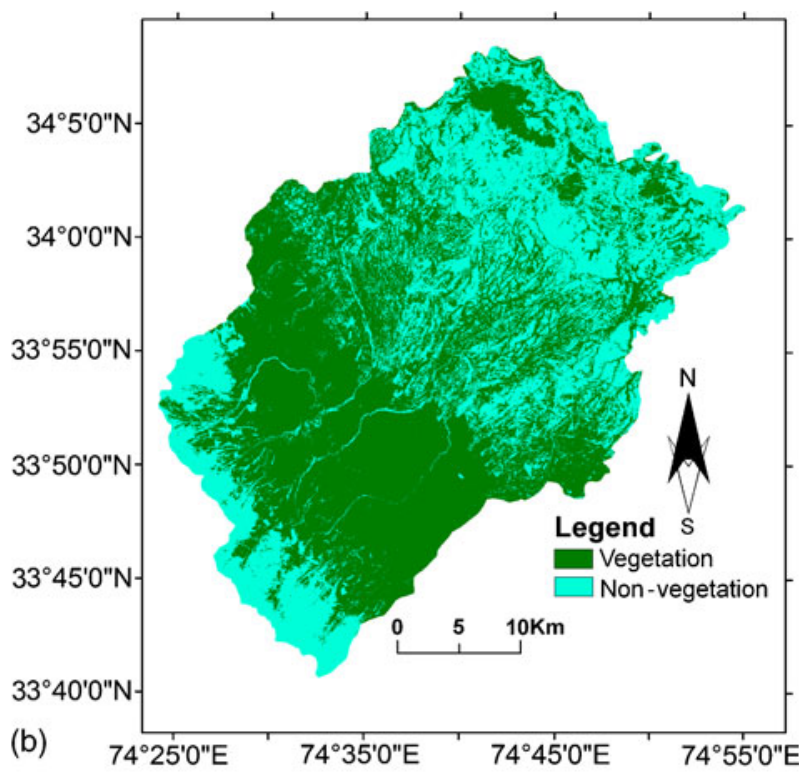

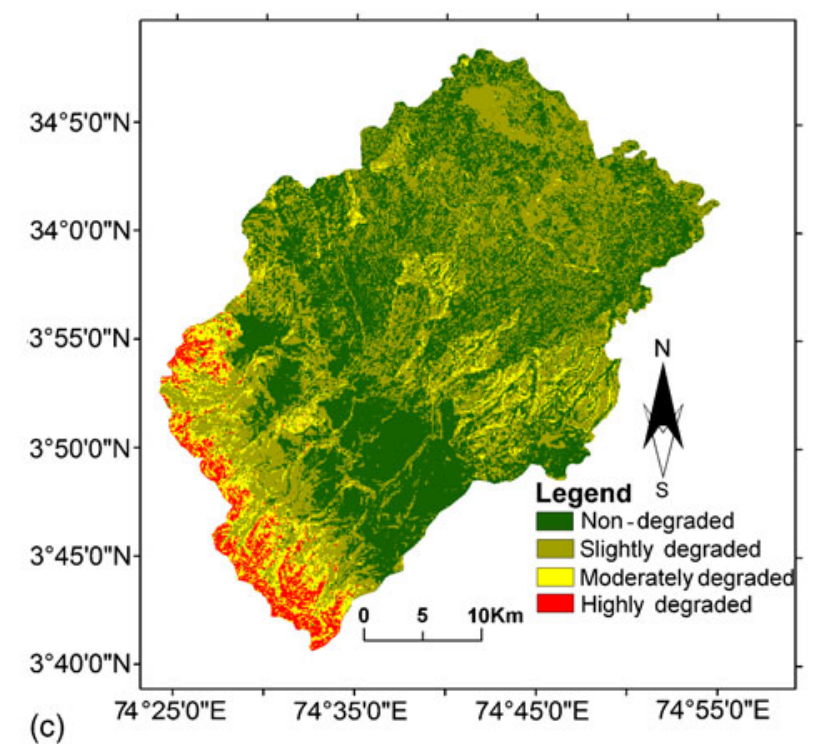

Figure 6. (a) Land-use/land-cover map of the study area as generated from supervised classification of 2008 Landsat ETM+ image using maximum likelihood classifier. (b) Vegetation distribution in the study area as derived from the NDVI. (c) Map depicting the status of land degradation in the study area as derived from the overlay analysis of land use/land cover, NDVI and slope. 
Table 3. Error matrix of the land-use/land-cover classification derived from the 2008 Landsat ETM+ image.

\begin{tabular}{lccccc}
\hline Class name & $\begin{array}{c}\text { Reference } \\
\text { totals }\end{array}$ & $\begin{array}{c}\text { Classified } \\
\text { totals }\end{array}$ & $\begin{array}{c}\text { Number } \\
\text { correct }\end{array}$ & $\begin{array}{c}\text { Producers } \\
\text { accuracy(\%) }\end{array}$ & $\begin{array}{c}\text { Users } \\
\text { accuracy }(\%)\end{array}$ \\
\hline Water & 0 & 0 & 0 & - & - \\
Forest & 5 & 5 & 5 & 100.00 & - \\
Bare soil & 0 & 0 & 0 & - & 100.00 \\
Meadows & 2 & 2 & 2 & - & - \\
Mountains & 0 & 0 & 0 & 100.00 & 100.00 \\
Snow & 1 & 1 & 1 & 100.00 & 75.00 \\
Karewas & 11 & 11 & 11 & 100.00 & 80.00 \\
Clouds & 3 & 4 & 3 & 100.00 & 75.00 \\
Paddy fields & 8 & 10 & 8 & 66.67 & 100.00 \\
Built-up & 3 & 4 & 3 & - & 100.00 \\
Cornfields & 3 & 2 & 2 & 50.00 & 100.00 \\
Boulder beds & 0 & 0 & 0 & 85.71 & 100.00 \\
Sparse veg & 2 & 1 & 1 & 75.00 & \\
Horticulture & 7 & 6 & 6 & & \\
Wetlands & 4 & 3 & 3 & & \\
Total & 49 & 49 & 45 & & \\
Overall classification accuracy $=91.84 \%$ & & & & \\
Overall kappa statistics & $=0.906$ & & & & \\
\hline
\end{tabular}

even $60-100 \%$ at different places in the study area (figure 3d). These values were then assigned class ranks for performing weighed overlay analysis in ArcGIS Spatial Analyst Module.

\subsection{Land use and land cover}

Land use/land cover map was prepared using knowledge-based supervised classification technique and

Table 4. Areal extent of the land use/land cover classified from $30 \mathrm{~m}$ Landsat ETM+ image of the study area.

\begin{tabular}{lr}
\hline Land use/ & Area $\left(\mathrm{km}^{2}\right)$ \\
land cover & \\
\hline Forest & 143.57 \\
Bare soil & 11.22 \\
Meadows & 55.81 \\
Wetlands & 32.21 \\
Snow & 14.49 \\
Karewas & 197.07 \\
Paddy fields & 142.96 \\
Cornfields & 36.43 \\
Horticulture & 308.18 \\
Built-up & 138.13 \\
Mountains & 98.12 \\
Clouds & 11.31 \\
Boulder beds & 5.88 \\
Sparse vegetation & 92.60 \\
Water & 3.20 \\
Total & 1291 \\
\hline
\end{tabular}

maximum likelihood classifier. The results reveal that out of the 15 covers mapped from the $30 \mathrm{~m}$ Landsat data, karewas with an area of $197 \mathrm{~km}^{2}$ is a predominant land-use class that is under land degradation due to reduction in vegetation cover, accounting for $15 \%$ of the entire study area, $37.8 \%$ of land is under agriculture and horticulture and mountains account for $7.6 \%$ of the total area. About $11.12 \%$ of the area is covered by forest and sparse vegetation occupies $7 \%$ of the total area. The snow cover accounts for an area of about $1 \%$. Built-up is a vital land-use class and holds about $10 \%$ of the total area due to rapid urbanization (figure 6a). Table 3 presents the results of the confusion matrix for the land-use/land-cover classification accuracy assessment. The overall classification accuracy was $91.84 \%$, with an overall kappa statistic of 0.906. The areal extent of land-use/land-cover classes is given in table 4 . The land-use classes were then assigned class ranks according to their role in assessment of land degradation.

Table 5. Areal extent of the land degradation classes derived from overlay analysis of slope, NDVI and land use/land cover in the study area.

\begin{tabular}{lc}
\hline Land degradation classes & Area $\left(\mathrm{km}^{2}\right)$ \\
\hline Non-degraded & 551.21 \\
Slightly degraded & 569.60 \\
Moderately degraded & 120.81 \\
Highly degraded & 49.40 \\
\hline
\end{tabular}


Table 6. Error matrix of the land degradation derived from the overlay analysis of slope, NDVI and land use/land cover.

\begin{tabular}{lccccc}
\hline Class name & $\begin{array}{c}\text { Reference } \\
\text { totals }\end{array}$ & $\begin{array}{c}\text { Classified } \\
\text { totals }\end{array}$ & $\begin{array}{c}\text { Number } \\
\text { correct }\end{array}$ & $\begin{array}{c}\text { Producers } \\
\text { accuracy(\%) }\end{array}$ & $\begin{array}{c}\text { Users } \\
\text { accuracy(\%) }\end{array}$ \\
\hline Non-degraded & 15 & 17 & 14 & 93.33 & 82.35 \\
Slightly degraded & 17 & 17 & 14 & 82.35 & 82.35 \\
Moderately degraded & 6 & 4 & 4 & 66.67 & 100.00 \\
Highly degraded & 2 & 2 & 2 & 100.00 & 100.00 \\
Total & 40 & 40 & 34 & & \\
Overall classification accuracy $=85 \%$ & & & & \\
Overall kappa statistics $=0.766$ & & & & \\
\hline
\end{tabular}

\subsection{Estimation of vegetation cover}

Vegetation cover is one of the most important biophysical indicators of soil erosion and therefore needs to be considered when attempting to measure the extent of land degradation. Vegetation cover can be estimated using vegetation indices derived from satellite images. Vegetation indices allow us to delineate the distribution of vegetation and soil based on the characteristic reflectance patterns of green vegetation (Jensen 2000). In this case, the NDVI is determined with Landsat using bands 4 (NIR) and 3 (red), respectively.

NDVI values are obtained in the range of 0.31 to 0.53 . Higher values are found in the dense forests and meadows followed by orchids. The lowest NDVI value is presented within areas having steep mountains and bare soil. The total vegetation area determined by NDVI is 74271.69 hectares, which accounts for $57.53 \%$ of the total area. Non-vegetated areas occupy 54831.01 hectares or $42.47 \%$ of the total area. The NDVI ranging from -0.3 to 0.53 was divided into five classes from negative to positive values using the overlay analysis in ArcGIS 'Spatial Analyst Module' (figure 6b).

\subsection{Classification and assessment of land degradation}

Although each individual indicator is helpful in describing an aspect of land degradation, it is useful in combining the results of vegetation cover, land use/land cover and slope, to determine areas which appear to be affected by land degradation for different indicators. Integrating the information from NDVI, land use/land cover and slope into four classes with different themes, weight and class ranks were assigned to perform the following overlay analysis. Areas with higher slopes (60$100)$ and low NDVI $(-0.3)$ values are assigned high ranks for land degradation and the areas with low slope (0-15) and higher values of NDVI
(0.5) were assigned low ranks for land degradation. Similarly, land-cover classes such as karewas, bare soil, etc., were put in high land degradation category and dense forest canopy in non-degraded category. The results obtained show that $42.69 \%$ of land is non-degraded, covering an area of 55121.33 hectares, $44.12 \%$ of land falls under slightly degraded category having an area of 56959.13 hectares, including wetlands, karewas and agricultural land. About $9.36 \%$ of the land is under moderate degradation category having an area of 12081.66 hectares, whereas $3.82 \%$ of land, which accounts for 4926.91 hectares of land, is under a highly degraded category. About $13.19 \%$ of the total area falls under moderate to highly degraded category comprising mostly of high elevated areas (table 5). The reason is that these areas do not support much vegetation cover due to steepness of slope and during the last decade there has been a rise in temperature within the study area. In general, this increased the length of dry spells and loss of vegetation cover and in particular areas of karewas as supported by temperature and precipitation data. The wetlands in the area are witnessing extreme eutrophication which is supported by NDVI results and were validated by the ground survey. This has resulted in tremendous degradation of this natural resource mostly because of weeds. Classification accuracy assessment in table 6 presents the results of the confusion matrix for land degradation. The overall classification accuracy was $85 \%$, with an overall kappa statistic of 0.766 . Overall accuracy of $85 \%$ is considered sufficient for large area protocols. However, a decline in predictive accuracy could have been due to differences between the resolution of the ground survey and that of the remote sensing data (figure 6c).

\section{Conclusion and recommendations}

The study demonstrates that remote sensing and GIS techniques are helpful in identification, assessment, monitoring, mapping and classification of 
degraded lands. We have attempted a methodology of implementing three important indicators of land degradation at a regional scale. This combines the estimates of vegetation cover, land use/land cover and slope. Areas where the suggested indicators are affected by land degradation have been defined. These areas are considered to be the prime targets for land degradation that warrant further study. Another area ripe for further research would be to develop and implement more indicators of land degradation in order to provide a more comprehensive picture of this complex phenomenon.

The implementation of the methodology described in this paper has proven successful in determining the spatial extent of various categories of degraded lands in the area. Slightly degraded areas can be recovered with the proper land use planning and detailed monitoring. Vegetation, land use/land cover and slope are important factors that help in determining the spatial extend of land degradation. Results show that karewas soils support most of the horticulture, viz., apple and almond plantation in the area are degrading. Therefore, it is recommended to monitor and manage these landscapes properly. Wetland eutrophication is a serious threat to the natural habitat of migrating birds and should be checked along with deforestation in the area. Land degradation indicators, however, are dynamic at time-scales longer than a year. Thus, to use the methods of this study to identify progressive land degradation, a longer record needs to be examined. The present scenario of land degradation in the area is very alarming and needs proper land use planning and management. Therefore, further research should be carried out by considering more indicators.

\section{Acknowledgements}

The authors are thankful to the Director, National Geophysical Research Institute, Hyderabad, India for granting permission to publish the paper. They would like to acknowledge USGS for online availability of Landsat data. They also wish to express their sincere gratitude to the anonymous reviewers, for their valuable comments and suggestions.

\section{References}

Abrol I P and Bhumbla D R 1971 Saline and alkali soils in India - their occurrence and management; World Soil Resources Report, pp. 41-42.

Chikhaoui M, Bonn F, Bokoye A I and Merzouk A 2005 A spectral index for land degradation mapping using ASTER data: Application to a semi-arid Mediterranean catchment; Int. J. Appl. Earth Observ. Geoinform. 7 $140-153$.
Dwivedi R S 1992 Monitoring and the study of the effects of image scale on delineation of salt-affected soils in the Indo-Gangetic Plains; Int. J. Remote Sens. 13(8) 1527-1536.

Dwivedi R S and Sreenivas K 1998 Delineation of saltaffected soils and waterlogged areas in the Indo-Gangetic Plains using IRS-1C LISS-III data; Int. J. Remote Sens. 19(14) 2739-2751.

Dwivedi R S, Ravi Sankar T, Venkataratnam L, Karale R L, Gawande S P, Rao K V S, Senchaudhary S, Bhumik K R and Mukharjee K K 1997 The inventory and monitoring of eroded lands using remote sensing data; Int. J. Remote Sens. 18(1) 107-119.

ENVIS (Environmental Information System Newsletter) 2003 State Environment Related Issues, Jammu and Kashmir, 14p.

ERDAS 1999 ERDAS Imagine Field Guide. 5th edn. (Atlanta, Georgia: ERDAS International).

FAO 1980 Report on the Second FAO/UNFPA Expert Consultation on Land Resources for Populations of the Future, FAO, Rome.

Jensen J R 1996 Introductory Digital Image Processing: A Remote Sensing Perspective; 2nd edn. (New Jersey: Prentice Hall), 172p.

Jensen J R 2000 Remote Sensing of the Environment: An Earth Resource Perspective (New Jersey: Prentice Hall), $361 \mathrm{pp}$.

Karale R L, Bali Y P and Sheshagiri R K V 1983 Soil mapping using remote sensing techniques; Proc. Indian Acad. Sci. 6(3) 197-208.

Kiage L M, Liu K B, Walker N D, Lam N and Huh O K 2007 Recent land-cover/use change associated with land degradation in the Lake Baringo catchment, Kenya, East Africa: Evidence from Landsat TM and ETM+; Int. J. Remote Sens. 28(19) 4285-4309.

Lal R 1990 Soil erosion and land degradation: The global risks; Adv. Soil Sci. 11 130-172.

Milton S J 1994 A conceptual model of arid rangeland degradation: The escalating cost of declining productivity; Bioscience 44(2) 70-76.

Mitchell C W 1981 Soil degradation mapping from Landsat imagery in North Africa and Middle East. In: Geological and Terrain Studies, Remote Sensing Society, London, pp. 49-68.

National Commission on Agriculture 1976 Report of the National Commission on Agriculture, Part V, IX, Abridged Report, Ministry of Agriculture and Irrigation, New Delhi, India.

Ning Wu 1997 Ecological situation of high-frigid rangeland and its sustainability: A case study on the constrains and approaches in Pastoral Western Sichuan China (Berlin: Dietrich Reimer Verlag).

Pal S K, Majumdar T J and Bhattacharya A K 2007 ERS-2 SAR and IRS-1C LISS III data fusion: A PCA approach to improve remote sensing based geological interpretation; ISPRS J. Photogram. Remote Sens. 61 281-297.

Pickup G and Chewings V H 1988 Forecasting patterns of soil erosion in arid lands from Landsat MSS data; Int. J. Remote Sens. 9(1) 69-84.

Pickup G and Nelson D J 1984 Use of Landsat radiance parameters to distinguish soil erosion, stability and deposition in Central Australia; Remote Sens. Environ. 16(3) 195-209.

Pickup G, Bastin G N and Chewings V H 1998 Identifying trends in land degradation in non equilibrium rangelands; J. Appl. Ecol. 35(3) 365-377.

Raza M, Ahmad A and Mohammad A 1978 The Valley of Kashmir: A Geographical Interpretation (New Delhi: Vikas Publishing House, Pvt. Ltd). 
Sharma R C and Bhargava G P 1988 Landsat imagery for mapping saline soils and wetlands in north-west India; Int. J. Remote Sens. 9(1) 39-44.

Stephen P R, Hicks D K and Trustrum N A 1981 Aerial photographic techniques for soil conservation research; Photogram. Eng. Remote Sens. 47(1) 78-79.

Survey of India 1975 Sheet No. $43 \mathrm{~K} / 9$ and $43 \mathrm{~K} / 13$, 2nd edn, 1:50,000, Govt. of India.

Symeonakis E and Drake N 2004 Monitoring desertification and land degradation over sub-Saharan Africa; Int. J. Remote Sens. 25(3) 573-592.

Szabolcs I 1992 Salinization of soil and water and its relation to desertification; Desertification Control Bulletin 21 32-37.

The Ministry of Economy, Trade and Industry of Japan (METI) and the National Aeronautics and Space Administration (NASA) 2009 Earth Remote Sensing Data Analysis Center (ERSDAC), http://www.gdem.aster.or.jp/

UNEP 1986 Sands of change: Why land becomes desert and what can be done about it; UNEP Environmental Brief No 2. United Nations Environment Program, Nairobi, Kenya.
UNEP 1998 Early warning of emerging environmental threats; Meeting report, 8 UNEP, Washington, USA.

United Nations 1994 Earth Summit - Convention on Desertification, Proceedings of the United Nations Conference on Environment and Development (UNCED), Rio De Janeiro, Brazil, Department of Public Information, United Nations, New York, USA.

United Nations 1997 Dryland degradation keeping hundreds of millions in poverty; Press Release: Secretariat of the United Nations Convention to Combat Desertification, Geneva, Switzerland.

Wadia D N 1975 Geology of India, 4th edn. (New Delhi: Tata McGraw Hill).

Wang G, Chen J, LI Q and Ding H 2006 Quantitative assessment of land degradation factors based on remotelysensed data and cellular automata: A case study of Beijing and its neighboring areas; Environ. Sci. 3(4) 239-253.

Zhang L, Yue L and Xia B 2003 The study of land desertification in transitional zones between the MU US Desert and the Loess Plateau using RS and GIS: A case study of the Yulin region; Environ. Geol. 44(5) 530-534. 